\title{
LA RESEMANTIZACIÓN DEL VANGUARDISMO EN CHIRAPU
}

\author{
THE RESEMANTIZATION OF THE AVANT-GARDE \\ IN CHIRAPU
}

\section{A RESSEMANTIZAÇÃO DA VANGUARDA EM CHIRAPU}

\author{
Alex Hurtado Lazo* \\ Universidad Nacional Mayor de San Marcos \\ Esandino - Estudios Andinos de Interculturalidad: quechua y aymara \\ alezh196@gmail.com \\ ORCID: 0000-0003-2722-6635
}

Recibido: $27 / 02 / 21$

Aceptado: $10 / 03 / 21$

* Bachiller en Literatura por la Universidad Nacional Mayor de San Marcos. Es miembro del Grupo de Investigación Esandino. Ha publicado los artículos "'Por la palabra se conoce la dirección del espíritu': Gamaliel Churata y la vanguardia en Chirapu (1928)" en Mitologías Hoy (2020) y "Chirapu (1928): Antero Peralta y el debate por la vanguardia" en Chirapu. Edición facsimilar (Universidad Ricardo Palma, 2021); además de diversas reseñas en revistas y medios digitales. 


\section{Resumen}

El descentralismo de la vanguardia histórica en el Perú permitió la emergencia de voces intelectuales en las regiones que reflexionaron acerca de su constitución como fenómeno en el campo cultural. En este artículo nos centraremos en la propuesta editorial de Chirapu (Arequipa, 1928) a través de su núcleo intelectual, el cual realizó en sus páginas una resemantización del concepto de vanguardia. Al partir de la definición de periferias internas como lugar de enunciación, buscaremos comprender las estrategias que utilizaron estos intelectuales para ubicar a este movimiento en su particularidad "indoamericana"; por otro lado, analizaremos los niveles de resemantización con la finalidad de ubicar en su identificación estética e ideológica un recurso de legitimación para el arte nuevo andino.

Palabras clave: Chirapu, resemantización, vanguardismo, periferia interna.

\section{Abstract}

The decentralism of the historical avant-garde in Peru allowed the emergence of intellectual voices in the regions that reflected on its constitution as a phenomenon in the cultural field. In the article, we will focus on the editorial proposal of Chirapu (Arequipa, 1928) through its intellectual nucleus, which carried out in its pages a resemantization of the avant-garde concept. Starting from the definition of internal peripheries as a place of enunciation, we will seek to understand the strategies that these intellectuals used to locate this movement in its "Indo-American" particularity; On the other hand, we will analyze the levels of resemantization in order to locate in their aesthetic and ideological identification a legitimizing resource for the new Andean art.

Keywords: Chirapu, resemantization, vanguardism, internal periphery.

\section{Resumo}

O descentramento da vanguarda histórica no Peru permitiu o surgimento de vozes intelectuais nas regiões que refletiram sobre sua constituição como fenômeno no campo cultural. Nesta pesquisa nos deteremos na proposta editorial de Chirapu (Arequipa, 1928) por meio de seu núcleo intelectual, que realizou em suas páginas uma ressemantização do conceito de vanguarda. A partir da definição das periferias internas como lugar de enunciação, buscaremos compreender as estratégias que esses intelectuais utilizaram para localizar esse movimento em sua particularidade "indo-americana"; Por outro lado, analisaremos os ní- 
veis de ressemantização para localizar em sua identificação estética e ideológica um recurso legitimador da nova arte andina.

Palavras-chave: Chirapu, ressemantização, vanguardismo, periferia interna.

A partir de los postulados de Nelson Osorio (1981), los estudios acerca de las vanguardias literarias latinoamericanas han dejado de percibirlas como un epifenómeno de su par europeo y han posibilitado, más bien, reparar en aquella particularidad que la diferencia y cohesiona. La indagación acerca de la originalidad llevó a Yazmín López Lenci (1999) a proponer que en la vanguardia peruana se realizó un proceso de resemantización, con lo que se desecha la idea de que haya sido producto de una "recepción deforme, imperfecta o atrasada, ni de una mera producción textual imitativa de patrones extranjeros" (p. 22). Esta operación implica una transformación del sentido primigenio - en este caso, del europeo- a una entidad distinta, pero con una conexión referencial (Zecchetto, 2011, p. 127). Lenci plantea que el movimiento intelectual de la época logra vaciar de sentido el término occidental de la vanguardia para "asumir una posición vital de revisión, enjuiciamiento y apropiación original del patrimonio literario y cultural" (p. 23). Esta actitud favorece el desarrollo de un pensamiento crítico por parte de los artistas y posibilita la oportunidad de establecer un arte auténticamente latinoamericano. En la nación peruana, esta posibilidad es más problemática, pues, como señalaba Cornejo Polar (1989), el sentido proteico de la literatura se debe a sus "dinámicos e imprevisibles modos de inserción en una sociedad que no es nunca la misma" (p. 190).

El vanguardismo en el Perú no tuvo una recepción favorable desde el primer momento. Por un lado, la hegemonía estética cuestionaba la artificialidad y estruendosidad del movimiento, ubicándolos como una copia acrítica del fenómeno europeo. 
Clemente Palma (1916) menciona respecto al primer esbozo vanguardista en el pais: "Puede que cuando se tranquilice, encuentre realmente la forma y la idea original que hoy quiere arrancar en manotones alocados" (p. 52; nuestras cursivas). Por otro lado, en el mismo bando revolucionario se suman voces discrepantes. César Vallejo (1926), por ejemplo, mencionaba: "[Para la Poesía nueva] no importa que el léxico corresponda o no a una sensibilidad auténticamente nueva" (p. 183, nuestras cursivas). Asimismo, Miguel Ángel Urquieta (1927) señala: "Hasta hoy, gran parte del arte nuevo, es nuevo en su presentación" (p. 75 , nuestras cursivas). El arte vanguardista no se constituye, para estos críticos, como un movimiento autónomo, original y trascendente, como sus ejecutores quisieron pretender.

En este campo complejo es que aparece Chirapu, con una respuesta frontal a estas lecturas pero que generan, de este modo, nuevas divergencias para su superación. De esta manera, nuestro interés recaerá en analizar las estrategias adoptadas por el equipo editorial, o núcleo intelectual, de Chirapu (1928) -Antero Peralta, Víctor Romero y Víctor Martínez Málaga- para resemantizar el concepto de vanguardia, exportado hacia este continente desde Europa, a través del contenido que ellos publicaron en las páginas de esta revista arequipeña. Este análisis, desde los postulados de la sociología de la literatura de Pierre Bourdieu en Las reglas del arte, demostrará la particularidad de esta publicación hemerográfica y sus límites en tanto producción heterogénea de la época.

\section{Chirapu, una revista en "pobres hojas de papel co- rriente"}

La efervescencia de los postulados vanguardistas durante la década de los años veinte encontró en las revistas un espacio favorable para su difusión y legitimación como movimiento artístico y político. El caso más emblemático al respecto fue el del poemario Ande de Alejandro Peralta, publicación alentada 
por el Boletín Titikaka (1926), órgano de difusión del grupo Orkopata cuya gesta "quedaría incompleta sino [sic] difundiera el éxito de sus publicaciones" (Editorial Titicaca, "Nota editorial", 1926). En este sentido, se establece una relación de operatividad entre las publicaciones periódicas vanguardistas y el campo literario: la búsqueda de validación - y de respaldo- hacia sus creaciones.

En Arequipa, a inicios del siglo XX, los escritores, reunidos en cenáculos modernistas como Aquelarre o Pakpaquería, fueron definiéndose artísticamente pero también políticamente con la llegada de las nuevas corrientes de pensamiento. Es mediante el Frente de Intelectuales, Artistas y Trabajadores (FIAT) en 1927 y, a inicios de 1928, con el grupo Los zurdos, que la vanguardia logró establecerse con mayor arraigo. Este último colectivo fue dirigido por Antero Peralta Vásquez, narrador, poeta e intelectual arequipeño, fundador de la primera célula aprista en esta ciudad del sur en 1924 y colaborador de Amauta y el Boletín Titikaka. Además, el grupo conformó una tribuna que llevó su firma: Chirapu, "órgano del grupo Los zurdos", según consta en las primeras portadas.

Esta revista fue una publicación mensual que tuvo siete números en total, aparecidos entre enero y julio de 1928. Según el Boletín Titikaka, en una reseña que realizó sobre la aparición de Chirapu en la sección "Nuestros canjes" (1928), menciona a los siguientes como miembros de Los zurdos: "Trabajan con Peralta, Vásquez, Tinajeros aymara, Rodríguez Escobedo y Romero arequipeños. Le colabora con frecuencia Jorge Núñez, de Puno y otros distinguidos escritores”. Para Wilfredo Kapsoli (1984), quienes integraron el grupo fueron Antero Peralta, César Atahualpa Rodríguez, Guillermo Mercado, Luis de Rodrigo, Armando Rivera, entre otros cuya documentación es de difícil acceso. Para nuestros fines, es necesario replantear estas informaciones. De acuerdo a Beatriz Sarlo (1992), las revistas, por su intención de "intervenir en la coyuntura", "informan sobre las costumbres intelectuales de un período, sobre las relacio- 
nes de fuerza, poder y prestigio en el campo de la cultura" (p. 15). En ese sentido, en este texto partimos de los datos que nos proporciona la revista para reformular la constitución del grupo más cercana a la original — pues sostener que Atahualpa Rodríguez o Guillermo Mercado tomaron las decisiones en la revista es difícil-y sus directrices editoriales.

De esta manera, determinamos que el núcleo intelectual estuvo conformado por Antero Peralta, el responsable explícito de Chirapu que escribió constantemente en los siete números; Víctor Romero, encargado de revisar las propuestas que llegaban a la "guarida", como lo señala en sus "Seis microscópicas bailables"; y Manuel Martínez Málaga, el artista que acompañó todos los números con sus maderas. Esta reformulación nos permite establecer las fuentes sobre las que demostraremos el proceso de "resemantización" en la línea editorial de la revista. Además, como un dato relevante para destacar la importancia de Chira$p u$, en sus páginas participaron escritores e intelectuales como Blanca Luz Brum, Carlos Oquendo de Amat, Emilio Armaza, Rómulo Meneses, Francisco Mostajo, entre otros. A pesar del formato sencillo "en pobres hojas de papel corriente", en sus cortos números encontramos un interesante debate acerca de la constitución del vanguardismo indoamericano, en términos de Peralta, y en la que se evidencia la complejidad del campo cultural de esta década.

Tanto Los zurdos como Chirapu participaron de la categoría espacial de periferias internas (Zevallos Aguilar, 2018), propuesta que parte del concepto de colonialismo interno ${ }^{1}, \mathrm{y}$ que considera la colonización no solo a nivel internacional sino también al interior de la nación por parte de los grupos hegemónicos contra determinadas etnias en los niveles económicos, politicos, sociales y culturales (González Casanova, 2006). Las periferias internas, por tanto, configuran sus proyectos luego de un reconocimiento de la situación de desventaja en la que se encuentran, con el objetivo de revertir sus situaciones desde una ofensiva beligerante como la realizada por las vanguardias. 
A partir de la vinculación de la región del sur andino peruano (Arequipa-Cusco-Puno) con tal categoría, observamos la configuración conflictiva generada especialmente en los espacios literarios a partir de la relación entre los grupos hegemónicos y los jóvenes intelectuales - pero también entre estos y sus aliados-que se abrogaron la representación andina, cuyo objetivo radicó en la legitimación del arte nuevo y de la periferia como un espacio validado, a partir de una operación resemantizadora, espacio desde el cual se pueda establecer un diálogo en las mismas condiciones con sus similares latinoamericanos. Sin embargo, al situar nuestro objeto de estudio en una periferia interna como Arequipa no estamos particularizando sus saberes, sino que, como añade Zevallos Aguilar, estos, al vincularse con las dinámicas de poder, se universalizan.

En las páginas de Chirapu, y especialmente en los escritos de su núcleo intelectual, se configura esa relación asimétrica y conflictiva a partir de las estrategias que plantean y que les permite constituirse como un campo intelectual y artístico alternativo con sus propias propuestas de modernización. Los textos de Antero Peralta, "El uno y vario del arte vanguardista", "Hacia nuestra liberación integral" y "Legítima defensa" proponen dos niveles en los que opera esta resemantización de la vanguardia desde las periferias internas, y por los que nos regiremos en la estructura de esta investigación: El artista e intelectual de vanguardia y la multiformidad del fenómeno. Complementaremos determinadas ideas con los textos "Acotaciones a la prensa criolla" y "Seis microscópicas bailables" de Víctor Romero y las maderas de Víctor Martínez Málaga.

\section{El intelectual y el nuevo sujeto creador de la vanguardia}

"Oiga transeunte [sic]: deténgase. Quiero descargarle una andanada de palabras. Présteme orejas" (Peralta 1928a, p. 2). De esta manera inicia Peralta su texto manifestario " $\mathrm{El}$ uno y vario del arte vanguardista”. Destaca la configuración del destinata- 
rio de sus palabras y, también, de su arte, pues se propone la idea de una obra que atraviese la vida cotidiana: el receptor es el hombre común, el que transita los espacios — también simbólicamente- de esta periferia interna. Además, a partir de ello, el arte nuevo se dinamizará en tanto su difusión y reproducción. Este dinamismo tiene su correlato en la brevedad de los escritos de los artistas de la vanguardia, pero también de la cantidad de hojas que las revistas incluyan: en el caso de Chirapu, estas no exceden a ocho. Sin embargo, también podemos señalar que, así como existe un nuevo receptor, se exige un nuevo productor, un tipo de artista que se aleje de la propuesta torremarfilista.

Al recorrer las páginas de las revistas vanguardistas de la época, podemos observar que el artista asume una conciencia de su ser histórico mediante sus escritos; es decir, recurre a la escritura para ejercer una influencia intelectual mediante las revistas. Según Bourdieu (2015), la autonomía del campo literario faculta al artista moderno, en un viraje paradójico, de la capacidad de poder intervenir en el campo político: "Para ello, tenía que producir una figura nueva, la del intelectual, inventando para el artista una misión de subversión profética, inseparablemente intelectual y política" (p. 197). Al no depender más de un tutelaje estatal o burgués, el artista intenta establecer un discurso crítico contra este aparato, pero también contra aquellos que no continúan con esta ruptura. La producción de esta posición autónoma posibilita la inserción simbólica del escritor intelectual en la masa, principalmente como azuzador o dirigente letrado.

Así lo entiende Peralta cuando define los parámetros en su propuesta vanguardista. Para lograrlo, realiza una comparación: "La palabra de arte de hoy no es la oda sentimental sino la arenga revolucionaria" (1928c, p. 3). La variación del discurso artístico es notoria: de un plano interiorizado, la poesía asume la función de dirección política del momento histórico en el que se encuentran. Añade: "No es, pues arrullando a su cara 
mitad como ha de cumplir su misión el artista de vanguardia sino traduciendo el calor de las masas, de cara a los problemas comunes" (p. 3). Queda establecido que, sin abandonar completamente su labor creativa, el artista vanguardista se aboca a una traducción de la problemática situacional: es decir, el poeta debe adoptar una posición clara y alejarse, de forma explícita, del arte por el arte; en otras palabras, ser un sujeto revolucionario.

Sin embargo, la posición de Peralta se especifica aún más al enraizar al artista con el espacio y la raza: "La raza tahuantisuyana de hoy, se entiende, constituida por la amalgama de indios, cholos y blancos nativos que comulgan con el nuevo espiritu del neoindianismo" (1928a, p. 2). Para complementar la idea acerca del neoindio ${ }^{2}$, es necesario hacer una pausa y referirnos brevemente a un texto anterior aparecido en el Boletín Titikaka. En "Indoamericanismo estético" (1927, p. 54), Peralta manifiesta que la tarea de renovación artística está reservada al neoindio, "producto de la fusión de razas en Indoamérica", en desmedro del indio, asumido como un sujeto antiguo, desfasado: "tengo poca fe en el avatar del espíritu netamente indio", añade. La pureza tanto biológica como cultural están descartadas para el arequipeño: quien erigirá la propuesta de renovación, esta que ha sido producto histórico de lo nativo y lo extranjero, de lo blanco, lo cholo y lo autóctono, como manifiesta. Más allá de las indeterminaciones que figuran en su concepción, nos interesa reconstruir al sujeto creador que nuestro autor, y con él Los zurdos, erige como figura vanguardista.

Peralta no busca situar al indígena como sujeto auténtico del nuevo arte, sino solo rescatar el motivo cultural para resemantizarlo; pues, así como el arte hegemónico, lo indígena ha quedado en el pasado: "I un pueblo, como el nuestro, que tiene un pasado de civilizaciones puede i debe CREAR" (p. 54), señala. Esto se aprecia con más claridad en la portada del primer número de Chirapu; incluso se observa el diálogo entre el texto manifestario y la madera de Martínez Málaga. El texto titulado 
"Chirapu"3 (Los zurdos, 1928) presenta a un auki de las punas rodeado de un espacio lúgubre que, al observar "a oriente", encuentra un mensaje de los dioses, de los protectores, quienes no son más que los autores de este texto: un arcoíris, un chirapu, en su traducción. Cabe destacar aquí lo siguiente: este mensaje es la "fé [sic] en el porvenir", "la fuente de inspiración del arte indigena", "la fuente de la cultura" (p. 1, mis cursivas). Es decir, es el motivo que permitirá la construcción de un nuevo arte y una nueva cultura. Chirapu propone la apropiación del ser indígena para una construcción de la nueva indianidad.

Como mencionamos, este texto dialoga con la madera de Martínez Málaga, en la que se aprecia al auki observando al chirapu, pero también una luminosidad, que es la esperanza y la posibilidad de redimir al indio a través de su mensaje. Sobre su arte, Málaga señala:

El alma de nuestro pueblo reflejada en sus inconfundibles costumbres, la naturaleza llena de color, de abierta atmósfera, de transparente y limpido aire, pueden alimentar los más acertados deseos o intentos de hacer un legitimo arte peruano (Ruiz Rosas, 2012, p. 11; nuestras cursivas).

La noción de alimentar el arte nacional con las costumbres y la naturaleza del pueblo recuerdan los postulados del neoindianismo, y es un criterio que rige la obra de Málaga en sus diversas manifestaciones.

El neoindio, por tanto, instrumentaliza los saberes indigenas para resemantizar el concepto de "nuestro arte". En tal sentido, Peralta y Los zurdos están validándose como sujetos creadores en consonancia con el fenómeno de revolución artística. Entonces, luego de esta reformulación surge la pregunta por el nuevo arte: la renovación antropológica, ¿qué engranajes del sistema literario ha remecido? 


\section{Una floración multiforme: la reformulación del campo literario}

Para comprender qué tensiones existen en el campo literario ${ }^{4}$, es preciso observar que el proceso de gestación del arte nuevo de la vanguardia es producto de las luchas entre un polo hegemónico - aquel que tiende a la "defensa de la rutina y la rutinización, de lo banal y la banalización, en una palabra, del orden simbólico establecido" (Bourdieu, 2015, p. 308)- y aquellos rupturistas que buscan la subversión del arte, el "retorno a la pureza de los orígenes" (p. 308). Ante ello, hemos visto cómo Chirapu resemantiza la idea de sujeto creador a partir de conceptos como el neoindianismo y la revolución. Pero también es preciso notar que este intelectual debe aprehender los marcos del campo en el que está actuando y para ello recurre a la metáfora del uno y vario: "El vanguardismo, fijese, en espíritu es uno, pero, en función es vario" (1928a, p. 2). A partir de esta idea, el arequipeño buscar ordenar un espacio que presenta fisuras en su organización.

El primer punto es el de la unidad, que "agita las conciencias por doquiera con el estímulo de la justicia social" (1928a, p. 2). Peralta atribuye a las escuadras vanguardistas una finalidad instrumentalizadora: "los cambios de dirección de la vida de los pueblos obedecen también a la acción de la literatura, del arte" (1928b, p. 4). Dicho objetivo, desde luego, era heredero de una corriente ideológica explícita: "La temática del movimiento vanguardista hai que buscarla en MARX" (1928c, p. 5). Por tanto, bajo la conceptualización de Peralta y la orientación de Chirapu, encontramos la participación de los intelectuales apristas y socialistas: Carlos Manuel Cox, Manuel Seoane, Rómulo Meneses, Carlos Oquendo de Amat o Gamaliel Churata. Esta aparente unidad, sin embargo, se complejizará con el segundo punto.

Por otro lado, "el segundo [lo vario] crea la floración multiforme, especialmente en el arte" (1928a, p. 2). Es aquí cuando 
se evidencia la divergencia de propuestas: si bien Peralta la explicita en el arte, también incidiremos en el aspecto político, campo que no resulta ajeno para las vanguardias literarias. De hecho, para los vanguardistas, los nexos entre arte y politica, especialmente la revolucionaria, son explícitos, pero encuentran matices necesarios como los sentenciados por Mariátegui: "No todo el arte nuevo es revolucionario, ni es tampoco verdaderamente nuevo" (1987, p. 18). La elaboración de un arte vanguardista y revolucionario, por lo tanto, va a ser una de las prioridades de este grupo de artistas de la década del veinte, aun para Los zurdos de Arequipa. De ahí el interés en insertarse en un debate y la creación de estrategias para lograr su legitimidad en el campo literario peruano.

La creación artística de "una bella caravana de ideas vivas", de "la palabra musculosa, dinámica, de vida ágil, inconfundible" (Peralta, 1928c, p. 4) que es la vanguardia establecerá en un primer nivel una oposición de los "pasadistas frente a la prepotencia de las huestes futuristas" (p. 3). Este arte nuevo, "fenómeno histórico, por lo mismo q' es fruto de la actividad humana" (p. 2), creado por el neoindio, se alejará del racionalismo frígido de los académicos y se sustentará "en lo profundo de las profundidades humanas y geoanimicas" (Peralta 1928a, p. 2); desde la sensibilidad, desde la emoción, "formemos NUESTRA ESTÉTICA, con el barro de nuestro suelo y el aliento de nuestra raza" (p. 2). Este concepto halla sus ecos en la propuesta de "vanguardia enraizada" de Alfredo Bosi (1991), quien señala que "[este proyecto estético] encuentra en su propio hábitat los materiales, los temas, algunas formas y, principalmente, el ethos que informa el trabajo de la invención" (p. 21). Es decir, la formulación del neoindianismo continúa justificando su existencia con el fundamento indigena, pero apropiado y reformulado por el nuevo sujeto para hacer frente a una oposición hegemónica que no responde a los impulsos de la época.

Sin embargo, desde un segundo nivel, notamos que la oposición existe incluso dentro de este frente amplio de "justicia 
social" que se anunciaba en "el uno". Esto se evidencia en dos textos de los aliados apristas Rómulo Meneses y Jorge Núñez Valdivia, quienes critican la "inutilidad" de las vanguardias literarias respecto del trabajo económico ${ }^{6}$. Pero encuentran en Antero Peralta un llamado a la unidad que repara en la particularidad del movimiento: "Nunca las acciones i reacciones históricas de un pueblo han marcado fases culturales uniformes, ni unilaterales" (1928b, p. 3; nuestras cursivas). Esta visión, postulada desde el campo literario, da cuenta de la heterogeneidad de propuestas integrales que se formulan dentro de las periferias internas, asî como también de una reivindicación del desarrollo artístico de la época, formadora además de su personalidad, aunque menospreciada por las fuerzas revolucionarias: "Verdad que el resorte más poderoso i determinante del fenómeno social es el factor económico, pero no es menos cierto también que las otras manifestaciones espirituales, informadas por la aspiración teorética del momento [...] preparan la conciencia colectiva" (p. 4).

Cabe señalar que esta sentencia de Peralta no es espontánea, sino que es generada a partir de un debate acaecido en las mismas páginas de la revista, lo que posibilita una delimitación más profunda de la propuesta editorial de Chirapu. Esta posición se reafirma con Víctor Romero, quien ante la creciente demanda de que la revista se pronunciara únicamente en aspectos económicos y sociales (1928b, p. 6), propone el fortalecimiento de la "ortografía neoindia" de Francisco Chuquiwanka Ayulo para así reformular lo que se ha tomado hasta ese momento como convencional, tradicional, pasatista, y "hacerles vibrar a tono con la última pulsación cósmica” (1928a, p. 5). A este pedido se suma Gamaliel Churata en su comunicación con Peralta incluido como "Fragmentos de una carta" en el número del mes de abril. Y es en este espacio que además se añaden voces beligerantes desde otras regiones de la periferia interna, como la de José $Z$. Portugal en Sicuani, que amplían a nivel 
geográfico y simbólico la importancia de estas reflexiones artísticas y culturales.

\section{Conclusiones}

Las estrategias argumentativas de Antero Peralta en sus ensayos de Chirapu, y con estos la orientación que asume la revista por su calidad de director, tienen la finalidad de lograr la legitimidad del arte nuevo de la cual él y Los zurdos son representantes; es decir, son los intelectuales neoindios en los que germina un arte nuevo, de vanguardia enraizada. Esta producción, por lo tanto, no responde a la creación de una estética similar a la europea, expuesta a la calificación de arte puro, sino que, mediante una estrategia resemantizadora, elabora una vanguardia multiforme artísticamente y de marcado talante social. Esta propuesta, desde luego beligerante, desestabiliza los campos de poder, culturales y literarios en los que se inserta. Pero también, el desarrollo de la legitimación va a limitar los alcances que su propuesta quiso alcanzar, debido a que las demandas de representación no son resueltas en tanto que ese proceso no se concretó antes de su último número. Las luchas establecidas en el campo de poder, como el debate de 1928 entre socialistas y apristas, intervinieron en el desenvolvimiento de la revista, por lo que Chirapu tuvo un final abrupto. Sin embargo, podemos afirmar que la amenaza hacia un orden establecido se produjo desde una revista de "pobres hojas de papel corriente".

\section{Notas}

1 Por demás, la situación colonial de Indoamérica era percibida por los mismos vanguardistas, como Antero Peralta: "De aquí la urgencia de contemplar no sólo el peligro del imperialismo material sino también, con el mismo interés, del tutelaje cultural" (1928b, p. 4).

2 Existe una relación, a la vez conflictiva, con la propuesta de Uriel García. Ver "Neoindianismo" en Boletín Titikaka. 
3 Para una mayor comprensión de este texto manifestario, ver Hurtado Lazo, Alex, "Chirapu (1928): Antero Peralta y el debate por la vanguardia" en Chirapu. Edición facsimilar (Universidad Ricardo Palma, 2021).

4 Si seguimos a Bourdieu (2015), el campo literario ocupa una posición dominada, al igual que el campo cultural, dentro del campo de poder.

5 Debemos recordar que en estos primeros meses de 1928 todavía no se hace explícita la ruptura total entre apristas y socialistas. Tanto los primeros como los segundos se identifican con el marxismo, como lo evidencia el texto de Peralta, líder aprista en Arequipa.

6 Ver Meneses, Rómulo (1928), "Ismos, partos i disciplinas". Chirapu, n. 2, pp. 2-3. y Núñez Valdivia, Jorge (1928), "El rinrorranguismo indigenista". Chirapu, n. ${ }^{\circ}$, pp. 2-3.

\section{Referencias bibliográficas}

Bourdieu, P. (2015). Las reglas del arte. Génesis y estructura del campo literario. Barcelona: Anagrama.

Bosi, A. (1991). La parábola de las vanguardias latinoamericanas. En J. Schwartz (ed.). Las vanguardias latinoamericanas. Madrid: Cátedra.

Cornejo Polar, A. (1989). La formación de la tradición literaria en el Perú. Lima: CEP.

Editorial Titicaca (agosto de 1926). Nota editorial. Boletín Titikaka, 1,1 .

González Casanova, P. (2006). Colonialismo interno. Una redefinición. En A. Borón, J. Amadeo, S. González (eds.). La teoria marxista hoy. Problemas y perspectivas. Buenos Aires: CLACSO.

López Lenci, Y. (1999). El laboratorio de la vanguardia literaria en el Perú. Lima: Horizonte.

Los zurdos (enero de 1928). Chirapu. Chirapu, $1,1$.

Osorio, N. (1981). Para una caracterización histórica del vanguardismo literario hispanoamericano. Revista iberoamericana, 47(114), 227-254.

Palma, C. (1916). Notas de artes y letras. En M. Lauer. La polémica del vanguardismo. Lima: UNMSM. 
Peralta, A. (1927). Indoamericanismo estético. Boletín. Editorial Titikaka, setiembre 1927, 2.

- (1928a). El uno y vario del arte vanguardista. Chirapu, 1, 2.

- (1928b). Hacia nuestra liberación integral. Chirapu, 3, 3-5.

Romero, V. (1928a). Acotaciones a la prensa criolla. Chirapu (2), 4-5.

Romero, V. (1928b). Seis microscópicas bailables. Chirapu (3), 6-8. Urquieta, M. A. (1927). Izquierdismo y seudoizquierdismo artísticos. En M. Lauer. La polémica del vanguardismo. Lima: UNMSM.

Vallejo, C. (1926). Poesía nueva. En M. Lauer. La polémica del vanguardismo. Lima: UNMSM.

Zecchetto, V. (2011). El persistente impulso a resemantizar. Universitas. Revista de ciencias sociales y humanas, 14, 127-142.

Zevallos Aguilar, U. (2018). Culturas de las periferias internas en la región andina. El grupo Orkopata (1926-1930). En U. Zevallos Aguilar. Literatura y cultura en el sur andino. Cusco-Puno. Cusco: Ministerio de Cultura. 